\title{
UM CONTO EXCEPCIONAL DE RUBEM FONSECA
}

\author{
Hudinilson Urbano*
}

\begin{abstract}
RESUMO: O objetivo deste artigo é analisar um conto de Rubem Fonseca, "O pedido", considerado por nós como um conto de caracteristicas excepcionais dentro do livro Feliz Ano Novo e mesmo dentro da obra geral do escritor, principalmente em termos de temática e linguagem. Os outros 14 contos do livro são tematicamente cruéis e violentos $e$, verbalmente ofensivos e indecorosos, o que procuramos demonstrar, analisando paralelamente, para simples confronto, o conto "Botando praquebrar".
\end{abstract}

PALAVRAS-CHAVE: literatura; linguagem; oralidade; narrativa.

\section{Introdução}

eferimo-nos ao conto "O pedido", um dos contos do livro
Feliz Ano Novo, de Rubem Fonseca, censurado em dezembro de 1976 (Portaria 8.401-B, de 15.12.76), mais ou menos um ano após sua publicação, por "ofender a moral e os bons costumes", segundo o Ministro da Justiça Armando Falcão; pelo "culto à violência e à apologia do crime", segundo o juiz Bento Gabriel da Costa Fontoura, na sentença considerando improcedente a ação promovida pelo autor; ou, segundo outras vozes, por conter temas marcados pelo erotismo e violência; pelo linguajar indecoroso etc. A própria orelha da pu-

- Universidade de São Paulo-USP. 
blicação propalava: "Um livro engraçado e mordaz, mas também cruel e violento, que mostra a realidade inquietante de um mundo ameaçadoramente destrutivo e corrupto". Ainda à margem da censura e dessas vozes, são muitos os questionamentos e as qualificações negativas sobre o livro: literatura de crueldade marcante em quase todos os quinze contos (Opinião, de 24.10.75); "a mensagem central da coletânea é a violência, que se baseia em tipos patológicos e retrata a realidade do submundo criminoso de uma grande cidade" (O Globo, 10.4.80); O caso Rubem Fonseca - Violência e erotismo em Feliz Ano Novo (Silva, 1983) etc.

A coletânea compõe-se de quinze contos; segundo alguns: "15 contos de crimes" (Frejat, 1977), marcados pela "violência, que é um traço comum que atravessa todos os contos de Feliz Ano Novo" (Silva, 1978), a saber: "Feliz Ano Novo", "Corações solitârios", "Abril, no Rio, em 1970", "Botando pra quebrar", "Passeio noturno - Parte I"; "Passeio noturno - Parte II", "Dia dos namorados", "O outro", "Agruras de um jovem escritor", "O pedido", "O campeonato", "Nau catrineta", "Entrevista", "74 degraus", "Intestino grosso".

Para qualificar o livro como violento, erótico, verbalmente agressivo, análises e comentários são feitos praticamente sobre todos os contos; o único sobre o qual os analistas e críticos coerentemente silenciam ê o "O pedido".

Sob o aspecto da violência, Silva (1983:61-62) distribui os contos do livro em três grupos, a saber: 1) "narrativas onde a violência apresenta-se de forma inequivoca, real, onde o uso do braço armado, da força, é a solução final para os conflitos desenvolvidos ao longo dos contos": "Feliz Ano Novo", "Botando pra quebrar", "Passeio noturno I", "Passeio noturno II", "Dia dos namorados", "O outro", "74 degraus" e "Entrevista"; 2) "contos em que a violência apresenta-se mais freqüentemente no uso da cultura, que no 'uso da força'": "Corações solitários", "Abril, no Rio, em 1970", "Agruras de um jovem escritor", "O Campeonato" e "Nau Catrineta"; 3) um conto em que se utiliza de "um modo violento de narrar, agredindo a linguagem literária-padrão, pro- 
duzindo um texto quase aliterário e servindo-se dele para justificar essas suas opções. [...] A solução que se vê para os problemas que enfrenta como escritor é mais uma vez a violência, que atingirá padrões literários, mais temidos que respeitados": "O intestino grosso". Como se vê, o autor deixa de lado voluntariamente "O pedido"; nem poderia ser diferente, a louvar-se nos rótulos atribuidos aos três grupos acima.

Há comentários que focalizam a obra sob a temática da marginalidade urbana, da realidade violenta das grandes cidades, ou que apontam a quantidade de palavrões e obscenidades das cenas, referindo-se, coerentemente, ora a uns ora a outros contos. Mas desconhecemos qualquer referência ao "O pedido", que, como veremos, não se presta realmente a fundamentar qualquer dessas afirmações e qualificações.

Nem a decisão ministerial nem a sentença puderam se alicerçar particularmente nesse conto. O próprio juiz Costa Fontoura fundamentou-se em apenas cinco contos, transcrevendo alguns trechos deles, garantindo haver "um denominador comum consistente na inusitada violência contra a pessoa humana, aurelada por uma sugestão de impunidade." (Jornal do Brasil, 8.4.80). Na sentença, mudando a orientação dos argumentos acusatórios, o juiz, direta ou indiretamente, enquadra a obra sub judice em três pontos: "falou-se bastante sobre o erotismo e olvidou-se a violência. Falou-se bastante da linguagem e olvidou-se o conteúdo.", ou seja: erotismo, violência e linguagem.

\section{A regra e a exceção}

Fazendo abstração de muitos outros aspectos, dentro dos quais é possivel considerar "O pedido" como um conto de exceção no contexto dos quinze de Feliz Ano Novo, podemos afirmar que "O pedido" foge totalmente à classificação dos demais, seja em termos de conteúdo (erotismo e violência), seja em termos de linguagem (vocabulário obsceno). 
Preliminarmente, apenas a título de contraponto e suporte de nossas considerações, escolhemos como representante (poderia ser qualquer outro) da regra temática e lingüística da coletânea de Feliz Ano Novo o conto "Botando pra quebrar", ${ }^{1}$ classificado linhas atrás como uma narrativa de violência explícita, embora, no nosso entender, muito distante na carga de violência do conto-título, por exemplo, e de outros. Cremos que poderia estar perfeitamente incluido também no grupo três, uma vez que abundam termos obscenos, afora expressões chulas, girias, termos vulgares: fudidão, fudido, aporrinhado, filho da puta (3 vezes), puta merda (5 vezes), porra, porrada, puto, piçudo, cagalhão, sacana, sacaneado, esporrenta, babaca, embucetar, cagada, bicha (3 vezes), bichona, viado (2 vezes), caralho, virar o fio, bunda mole etc.

"Botando pra quebrar" relata, em cerca de quatro páginas, o episódio ocorrido com o narrador-personagem, um marginal recémegresso da cadeia, possivelmente de baixa ou nenhuma escolaridade, que, pelo "seu passado, tendo andado tanto tempo preso", não conseguia nem conseguiria emprego algum:

Eu estava meio fudidão sem arranjar emprego e aporrinhado por estar nas costas de Mariazinha, que era costureira e defendia uma grana curta que mal dava prą ela e, a filha. De noite nem tinha mais graça na cama, ela perguntando, arranjou alguma coisa? Teve mais sorte hoje? E eu me lamentando que ninguém queria empregar um sujeito com a minha folha corrida; só malandro como o Porquinho que estava a fim de eu ir apanhar pra ele uma muamba na Bolivia, mas nessa transa eu podia entrar bem, era só os homens me patolarem de novo que eu pegava uns vinte anos. E o Porquinho respondia, se tu preferes ficar rufiando a costureira, o problema é teu. O filho da puta não sabia como é que era lá dentro, nunca tendo ido em cana; foram cinco anos e quando eu pensava neles parecia que a vida inteira eu não tinha feito outra coisa, desde garotinho, senão ficar trancado no xadrez, e foi pensando nisso que eu deixei o

Este conto foi analisado sob o aspecto lingüistico em Oralidade na literatura - O caso Rubem Fonseca. 
Porquinho fazer pouco de mim na frente de dois bunda mole, morrendo de ódio e vergonha. (trecho inicial)

Pressionado pelas circunstâncias, "já topando o que desse e viesse, menos complicação com os homens", acaba arranjando um subemprego informal de leão-de-chácara numa boate, mas trabalha apenas uma noite. É que, destratado pelo dono por causa de uma bicha importante, cuja entrada, seguindo instruções do dono ("bicha louca, crioulo e traficante não entram, entendeu?"), tentava impedir, acabou provocando em seguida uma briga generalizada, prevendo que seria "mandado embora no fim do serviço":

Ai foi aquela cagada, o pau quebrou que parecia um trovão, de repente tinha uns dez caras brigando, nego que levava a sobra também dava, e entrava no conflito, corri pra dentro do bar e não sobrou uma garrafa, os lustres foram pra pica, a luz apagou, um ouriço tremendo que quando acabou só deixou em pé parede de tijolo. Depois que a policia chegou e foi embora, eu disse pro dono da casa, você vai me pagar o hospital e também o dentista, nesse rolo acho que perdi três dentes, me arrebentei todo para defender a sua casa, mereço uma grana de gratificação, a qual, pensando bem, quero receber agora. Agora. O dono da casa estava sentado, levantou, foi na caixa, apanhou um maço de dinheiro e me deu. Peguei meu embrulho e fui embora. Puta merda. (trecho final)

Como os demais contos, exceção feita ao "O pedido" e "Entrevista" (este apenas dialogado), "Botando pra quebrar" apresenta o foco narrativo de primeira pessoa. O narrador de primeira pessoa, por uma questão de coerência e verossimilhança, é em regra parcialmente ciente quanto aos fatos externos e totalmente não ciente quanto aos estados intimos dos personagens, mas, sendo autobiográfico, é totalmente ciente (e muitas vezes consciente) de si, que pode pôr a nu no relato, como ocorre aqui. Sujeito da enunciação narrativa, torna-se objeto principal do próprio relato, manifestando-se muito freqüentemente também como sujeito do enunciado narrativo. Observem-se 
quantas marcas de primeira pessoa são manifestadas na superfície do texto: só eu são cerca de 50; outros pronomes de primeira pessoa (me, minha, meus) são mais de 20, e primeira pessoa implicita nos verbos são cerca de 30 . A primeira pessoa tem a vantagem de a realização do ponto de vista resultar mais espontânea e natural, com mais convencimento do leitor.

O marginal narrador instala-se, pois, como objeto central da história e seleciona, e narra, friamente (até parece que com prazer e vanglória...) suas ações, com uma objetividade e autenticidade reveladoras de seu modo de ser e de se comportar frente à sociedade, como se observa claramente nos trechos inicial e final do conto, atrás transcritos.

Mas raramente revela seu interior, deixando escapar seus sentimentos (de ódio, vergonha, irritação, vazio, frustração, vingança). Quando o faz, percebem-se, ainda, recalque e despeito, enquadrados no campo da honra da marginalidade:

[...] e foi pensando nisso [no tempo em que havia ficado trancado no xadrez] que eu deixei o Porquinho fazer pouco de mim na frente de dois bunda mole, morrendo de ódio e de vergonha. (colchetes e grifos nossos)

Eu passava os dias fora, com vergonha de ver ela suando sem parar em cima da máquina de costura e eu sem dinheiro e sem emprego, e me deu vontade de quebrar a cara daquela filha da puta. (grifos nossos)

[Mariazinha] foi logo dizendo que havia encontrado um homem, sujeito decente e trabalhador, carpinteiro da loja de um judeu na rua do Catete, e que queria casar com ela. Puta merda. Senti um vazio por dentro. (colchetes e grifos nossos)

Fomos pro botequim, depois dele pedir licença ao Isac, e tomamos ùma cerveja e [pensei] ali estava outro filha da puta que eu devia matar de porrada, mas eu tava era entregando minha mulher pra ele, puta merda. (colchetes nossos) 
Vamos ver se eu entendi, eu disse, [ficando] piçudo porque tinha chamado aquele cagalhão de senhor enquanto ele tinha me chamado de burro. (colchetes e grifos nossos)

Mas [pensei] aqueles caras para ter toda aquela grana tinham que estar passando alguém para trás, vai ver era aqui o otário fudido às suas ordens, obrigado. (colchetes nossos)

Ai eu me lembrei do dono da casa, eu ia pra rua mesmo, puta merda, eu estava cansado de ser sacaneado, e ali na minha frente estava aquele pagode chinês, cheio de lustres e espelhos, pra ser quebrado, e eu ia deixar passar a chance?" (grifos nossos)

Por outro lado, embora sem registro explícito de datas e periodos, estima-se que a distância temporal entre o tempo da narração (tempo em que se realiza o ato de narrar) e o tempo da história ou dos fatos narrados é pequena, parecendo que o narrador-personagem relata sob efeito de forte emoção, provocado não só pela dramaticidade dos próprios fatos, como também por essa proximidade temporal, além de outros fatores, como a violência das adversidades de sua vida, de que é vitima mas também causa ao mesmo tempo.

Sem nos aprofundarmos nessa análise de cunho subjetivo e psicológico, frisamos que, envolvido com crimes (que nos parecem pequenos) e talvez por causa deles e de outros fatores (talvez até determinantes, como abandono, falta de escolaridade, formação e perspectivas, ambiente, desamor etc.), o marginal é fruto de uma violência social, em que entram os componentes da discriminação racial, social, da traficância etc. Mas ele é também pessoalmente violento, revelando toda sua agressividade, como um animal ferido, agindo irracionalmente. Sentese na história uma violência real nas agressões físicas, como o uso da força, murros, socos e garrafadas, embora sem mortes, e o emprego de tiros e facadas, como ocorre em muitos dos contos do livro.

Há quem considere a violência como resultado lógico da desu- . manização promovida pela sociedade de classes, ou como comporta- 
mento psiquicamente condicionado, ou ainda, simplesmente provocada pelo "mal" (Ascher, 1992). Sob qualquer faceta que se considere, parece-nos que "Botando pra quebrar" manifesta inequivocamente a violência humana. Segundo se vê, consoante acontece freqüentemente na obra de Rubem Fonseca, a solução é mais uma vez a violência. ${ }^{2}$

No que se refere ao erotismo, o conto é relativamente sóbrio, mas o registra, ainda que eufemisticamente: "De noite nem tinha mais graça na cama, ela perguntando, arranjou alguma coisa? Teve mais sorte hoje?".

A linguagem do protagonista retrata um individuo não escolarizado, desregrado, formado na escola da marginalidade e despudor, e reflete a emoção causada pelos fatos próximos ou em curso. Em três dias a trajetória do protagonista vai do fracasso como marginal ao abandono pela mulher (que ele é obrigado a entregar para outro homem), da humilhação por causa de um bicha à perda do emprego, dos dentes e do teto: está ferido fisica e moralmente. Tudo isso e mais a falta de perspectiva justificam a exacerbada agressividade da sua linguagem, aparentemente gratuita. Há uma impressão de desabafo, produzido de um só fôlego (observe-se a compactação paragráfica do texto, a ausência de pontuação dialogal...). Em menos de quatro páginas, o discurso narrativo está impregnado de vocábulos obscenos, como já assinalamos, sendo a maior parte deles, porém, de natureza mais catártica do que ofensiva. Só puta merda ele emprega cinco vezes, em momentos tragicamente dramáticos e localmente estratégicos do relato: quando Mariazinha lhe comunica que "um sujeito decente e trabalhador" "queria casar com ela". ("Puta merda. Senti um vazio por dentro."); quando ele se imagina entregando a mulher a outro homem

Naturalmente estamos nos referindo à violência "negativa". Pode-se, no entanto, observar a violência sob um ângulo positivo, até mesmo pela etimologia da palavra (vis = força). Nesse sentido, violência é irrupção de força, é "sempre uma inovação ou uma ruptura e as situações novas podem, em tese, ser melhores ou piores"; nesse sentido a "Lei Áurea, aparentemente, ao estabelecer uma sociedade de homens livres, realizou a boa violência."(Azevedo, 1999). 
("e ali estava outro filha da puta que eu devia matar a porrada, mas eu tava era entregando minha mulher pra ele, puta merda."); quando pressente que será mandado embora do serviço, único que conseguira encontrar como egresso da cadeia ("Vi logo que o sacana ia me mandar embora no fim do serviço e eu ia ficar de novo na rua da amargura. Puta merda."); quando termina seu desolado desabafo ("O dono da casa estava sentado, levantou, foi na caixa, apanhou um maço de dinheiro e me deu. Peguei meu embrulho e fui embora. Puta merda."). A agressividade verbal fica por conta do depoimento nervoso, excitado e exarcebado do personagem-narrador, de vez que as pouquíssimas falas dos demais poucos personagens de passagem são relativamente bem comportadas, sendo apenas a do dono da boate no momento de irritação a mais agressiva: "Porra, disse o dono, aonde foi que você aprendeu o serviço?".

"Botando pra quebrar", quanto à temática da violência e à linguagem realista e vulgar, tomadas como motivos para a cassação do livro, dá, pois, em maior ou menor escala, uma visão do que, nesses sentidos, ocorre nos demais contos do livro.

"O pedido", como veremos, constitui uma ilha no ambiente de violência, de crimes, de erotismo, de agressividade, que envolve a realidade social. Pode até ser realista, mas a realidade que retrata é a psicologia humana. E a linguagem é perfeitamente adequada a essa situação e a esse relato dos estados da alma. A própria estrutura narrativa pende para a tradicional, com começo, meio e fim, dentro de um enredo mais ou menos disciplinado, com indicação preliminar explicita e objetiva das circunstâncias contextuais, logo nas primeiras linhas (ver abaixo), com personagens mais ou menos bem delineados e caracterizados. E o texto é descompactado, a paragrafação é regular, alternada em tamanho, e a representação dos diálogos, embora sem traços de travessão, está próxima da normatizada.

"O pedido" narra, em cerca de três páginas e meia, o desesperado mas educado pedido de dinheiro que o português Amadeu, doente e necessitado, ousa fazer, envergonhado e humilde, ao patricio Joa- 
quim, com quem estava brigado fazia cinco anos, por motivo de que "Amadeu nem se lembrava mais". Mas Joaquim devia se lembrar e se lembrava, e o motivo era a frustração deste por causa do filho daquele, formado médico, que, entretanto, como Joaquim soube agora, tinha morrido em desastre de automóvel. A miséria de Amadeu e principalmente a morte do filho condoeram Joaquim, que se dispunha a atender $\mathrm{O}$ pedido, quando Amadeu, querendo agradar o patrício, pergunta-lhe sobre seu filho. Joaquim, "como se tivesse levado um choque", "jogou o dinheiro de volta dentro do cofre", desabafando aos brados:

O vagabundo não faz nada, nem para garrafeiro serve. Dorme o dia inteiro e à noite sai para passear. Um homem de mais de trinta anos vivendo às custas do pai [...] Um dia eu o mato, o parasita inútil.

Amadeu entristeceu-se e pensou: "Antes um filho morto". "E uma lágrima seca, feita quase somente de sal, escorregou do seu olho, uma lágrima pelo filho dele e pelo de Joaquim". Este se arrepende, reconsidera, e resolve dar o dinheiro a Amadeu, que, porém, tristemente, já havia se retirado, sem ouvir os gritos de chamamento de Joaquim, que insistia: "Amadeu! Amadeu! Volta, eu te dou o dinheiro, volta!", "enquanto escorriam pelo seu rosto lágrimas abundantes e úmidas de homem gordo e forte." (trecho final).

O relato começa com um pequeno flash back, dois dias antes:

Durante dois dias Amadeu Santos, português, viúvo, biscateiro, rondou o depósito de garrafas de Joaquim Gonçalves, sem coragem de entrar. Mas naquele dia chovia muito e Amadeu estava cansado, com a perna doendo do reumatismo. Além disso a bronquite crônica fazia-o tossir sem parar.

O foco é, excepcionalmente em relação aos demais contos, de terceira pessoa, o que permite a onisciência pelo narrador dos fatos (acontecimentos físicos, externos) e do interior (acontecimentos men- 
tais) dos dois personagens em conflito, em decorrência de eventos passados refletidos no presente. $O$ foco narrativo de terceira pessoa tende amiúde a dar à linguagem menor grau de informalidade do que a narrativa de primeira pessoa (Spenser \& Gregory, 1974:105). Por outro lado, a terceira pessoa, em princípio, rejeita a intimidade do narrador com o leitor, o que não impede que o ficcionista encontre estratégias de colocar o interior dos personagens em intimidade com o leitor. Antes, o narrador penetra, ou pensa penetrar, não só nos fatos singulares, mas sobretudo nos temores, lembranças, ansiedades, sensações, pensamentos e sentimentos (de pena, de vingança, de vergonha, de inveja, de humilhação, de mágoa, de raiva, de tristeza, de mesquinhez) dos personagens, inclusive sob a perspectiva ora de um ora de outro, desnudando-os, dessa forma, perante o leitor, nos instantes cruciais do diálogo:

[...] desde que brigaram por motivo que Amadeu nem se lembrava mais. [...] Mas Joaquim devia saber, e isso tornava ainda mais constrangedora a visita de Amadeu. (grifos nossos)

Amadeu era, na sua lembrança, um homem forte e bonito e à sua frente [pensava] estava um rebotalho magro e abatido, visivelmente minado pelas privações e pela doença.

Como estás, Joaquim? disse Amadeu, sem coragem de lhe estender a mão. (colchetes e grifos nossos)

Não me queixo, disse Joaquim imaginando qual seria o propósito da visita de Amadeu. [...] Mas os negócios não são mais como antigamente, acrescentou Joaquim, já prevendo um possivel pedido de dinheiro. Não creio que ele tenha a audácia de me pedir alguma coisa, pensou Joaquim, afinal somos inimigos, não nos falamos há anos. (grifos nossos)

Joaquim voltou a fazer suas contas no papel, mas, de vez em quando, levantava os olhos e observava Amadeu. Somos da mesma idade mas eu não estou assim acabado, pensou com 
uma sensação amarga de desforra. Também sentiu, bem no intimo, um sentimento de pena, contra o qual lutou. Nos últimos cinco anos ele esperava aquele momento de vingança. Mas não sentia nenhum prazer. (grifos nossos)

No fundo de suas olheiras doentes, seus olhos estavam opacos de vergonha.

No dia em que Carlos se formou, Joaquim, sentindo-se pessoalmente afrontado, deixara de falar com Amadeu. (grifo nosso)

Passei anos invejando um morto, pensou ele. (grifo nosso)

Tenho vergonha [de pedir dinheiro à nora], disse Amadeu. Ele sentia como se estivesse nu, no meio de uma praça, e sujo. Mas estava disposto a agüentar a sua humilhação até o fim. (entre colchetes e grifos nossos)

A miséria de Amadeu, e principalmente a morte de seu filho doutor, haviam dissipado parte do antigo ressentimento. (grifos nossos)

Amadeu percebeu que Joaquim ia the emprestar o dinheiro, e em sua mente começaram a desfilar imagens de sua vida nova na Bahia, com a nora (que não se casara novamente) e o neto. [...] Seu coração se encheu de carinho pelo patricio e amigo, [...] Preciso dizer alguma coisa boa para ele, pensou Amadeu, até agora só contei as minhas desgraças e pedi dinheiro. (grifos nossos)

Por que me perguntas uma coisa dessa?, falou Joaquim com mágoa maior do que a raiva que sentia. (grifos nossos)

Eu não sabia... disse Amadeu tristemente. Antes um filho morto, ele pensou. E uma lágrima seca, feita quase somente de sal, escorregou do seu olho, uma lágrima pelo filho dele e pelo filho de Joaquim. (grifo nosso)

Joaquim ficou sentado um instante curto. Eu não sou essa pessoa, ele pensou envergonhado com sua mesquinhez e [...] (grifos nossos) 
A simples seleção anterior parece clara e suficiente para revelar um recorte de fatos e sentimentos totalmente contrários aos dos demais contos de Feliz Ano Novo, como exemplifica "Botando pra quebrar". Os fatos não transcendem violência social nem erotismo, embora possam manifestar certa dureza existencial, e os sentimentos, uns nobres outros menos, aparecem em conflito, assim como são denunciados freqüentemente na psicologia humana de todos os tempos. A seleção e o tratamento deles constroem uma narrativa que vale como um exame e um diagnóstico psicológicos sérios e serenos, sem os matizes e o clima de violência, agressividade e erotismo presentes nos demais contos.

Embora sem querermos nos aprofundar na análise do enredo recortado e do perfil momentaneamente retratado pelo autor/narrador, ressaltemos apenas que o conto não só faz contraste com os demais contos, mas ele mesmo, internamente, reproduz contrastes situacionais, físicos e psicológicos, como ingredientes selecionados pelo autor/narrador, com vistas a reproduzir momentos e porções da essência da alma humana. Assim, dentro da situação pedinte/doador, encontram-se dois amigos de infância e adolescência, agora - ao menos por momentos - inimigos: um, rebotalho, magro, abatido, cansado, doente, outro, gordo, forte e sadio; um, viúvo, outro, casado; um, pobre, biscateiro, outro, comerciante bem sucedido; um, pai de filho médico, desaparecido em desastre, outro, pai de filho vagabundo, parasita e de presença perturbadora; um, humilde e envergonhado pela situação constrangedora em que se viu obrigado a se colocar, outro, orgulhoso e vingativo etc.

Durante o encontro, porém, mudam-se os sentimentos e as atitudes: um enchendo-se de carinho pelo patricio e de alguma forma reconfortado com o filho morto ("Antes um filho morto."), outro, abandonando os apetites de vingança, reconhecendo o patricio pedinte como "amigo". E o escritor encontrou a fórmula perfeita, mais uma vez por confronto, para retratar as facetas da alma humana em conflito: 
E uma lágrima seca, feita quase somente de sal, escorregou do seu olho, uma lágrima pelo filho dele e pelo filho de Joaquim.

Mas ao chegar à rua, esta estava deserta. Joaquim ainda gritou o nome do amigo algumas vezes, enquanto escorriam pelo seu rosto lágimas abundantes e úmidas, de homem gordo e forte.

Por outro lado, a linguagem, corroborando a sobriedade do tema, seu tratamento e a caracterização dos personagens, é comedida, beirando o padrão culto, sem concessões à variedade popular. Sendo uma narrativa em terceira pessoa, a linguagem revela-se bastante referencial e razoavelmente neutra em termos de expressividade espontânea e, mais, de subjetividade emotiva. Não aparecem manifestações pessoais explicitas do narrador com a freqüência natural das narrações de primeira pessoa. Entretanto não deixa de revelar feição de narrativa oral, com uma linguagem mais ou menos distensa. Assim, o estilo é coloquial, um coloquial sóbrio, sem rebuscamentos formais, que aproxima, com naturalidade, tema e leitor. Note-se um vocabulário restrito, simples, comum, conformando-se, realmente, mais com o dialeto culto. Observe-se, ainda, a pouca diversificação dos verbos dicendi e sentiendi, estratégia que dá um tom coloquial, com mais destaque ao conteúdo do dizer, do pensar e do sentir do que a sua forma: dizer (12 vezes), perguntar (2), responder (2), gritar (2), pensar (6), sentir (5); até o pleonasmo "sentir...um sentimento"), em oposição a imaginar, falar, repetir, balbuciar, protestar (uma vez cada).

É de se observar também o exclusivo emprego do discurso direto em relação ao discurso indireto, deixando os personagens falarem direta e livremente, com a força e expressividade que as situações exigiam.

Um indice de emprego e construções cultos manifesta-se também no uso exclusivo do verbo haver em relação ao ter no pretérito mais-que-perfeito composto (haviam emigrado, havia se casado, haviam dissipado, haviam feito) e a construção freqüente do mais-queperfeito simples: morrera, terminara, deixara, desmaiara, tivera, fora, chegara. 
A estruturação frásica também é singela, muita coordenação comparada à subordinação (e subordinadas de pouca complexidade), ordem direta.

\section{Conclusão}

Cremos ter deixado claro que, do confronto entre o conto "Botando pra quebrar", tomado como exemplo e representante dos contos classificados como violentos quanto ao tema e à linguagem, que é a regra em Feliz Ano Novo, e o conto "O pedido", resulta que, sendo aquele a regra, este pode ser considerado exceção à regra.

Se de um lado os dois são contos de história episódica, verdadeiras sinteses de dramas sociais e existenciais, vazados num estilo coloquial com feição de narrativa oral, muitos são, porém, os pontos contrastantes, que os classificam em posições diametralmente opostas. Mesmo no estilo coloquial, que se atribui aos dois, há que se opor claramente o estilo coloquial popular, até vulgar de um, ao estilo coloquial culto, ou próximo desse rótulo, do outro. Em "Botando pra quebrar" as situações são tensas, brutais, tumultuosas e as palavras as reproduzem nua e cruamente, sem veladas imagens e cuidados, enquanto em "O pedido" as situaçōes são narradas com serenidade e as palavras usadas com sobriedade, como aliás convém no tratamento dessas situações e do diálogo de pessoas em conflito existencial.

\footnotetext{
ABSTRACT: The purpose of this paper is to analyse a tale of Rubem Fonseca, "O pedido", considered by us with excepcional characteristics in the book Feliz Ano Novo and even inside of the writer's general work, mainly in terms of thematic and language.
}

KEYWORDS: literature; language; orality; narrative. 


\section{Bibliografia}

ASCHER, N. (1992) Folha de S. Paulo, São Paulo, 29.3.92. Mais.

AZEVEDO, A. Junqueira de (1999) Uma violência contra brasileiros. Jornal da USP, USP, 20 a 26.9 .99 , p. 2.

COSTA, F. M. (1980) O mundo torto e cruel de Rubem Fonseca, Opinião. Rio de Janeiro, 8.4.80.

FREJAT, J. (1977) Jornal do Brasil, Rio de Janeiro, 19.1.1977.

SILVA, Dionísio da (1983) O caso Rubem Fonseca. Violência e erotismo em Feliz Ano Novo. São Paulo: Alfa-Omega.

SPENCER, J.; GREGORY, M. J. (1974) Um enfoque do estudo do estilo. Lingüistica e estilo. São Paulo: Cultrix/Edusp.

URBANO, H. (2000) Oralidade na literatura. O caso Rubem Fonseca. São Paulo: Cortez.

Jornal do Brasil, Rio de Janeiro, 8.4.80.

Opinião, Rio de Janeiro, 24.10.1975.

O Globo, Rio de Janeiro, 10.4.1980. 